In: BioSocieties (2015) 10(4): 389-399. doi:10.1057/biosoc.2015.38

\title{
Editorial essay:
}

\section{Neuroscience beyond the laboratory: neuro knowledges, technologies} and markets [last version before submission]

Published as part of special issue on 'Neurosciences beyond the laboratory' in BioSocieties

Special issue editors:

\section{Tanja Schneidera,b, ${ }^{*}$ and Steve Woolgar ${ }^{c, d}$}

a Institute of Sociology, University of St. Gallen, Tigerbergstr. 2, 9000 St. Gallen, Switzerland, b Institute for Science Innovation and Society (InSIS), University of Oxford, Oxford, UK. Email: tanja.schneider@unisg.ch * Corresponding author.

c Tema T, Linköping University, Linköping 58183, Sweden, d Saïd Business School, University of Oxford, Park End Street, Oxford OX1 1HP, UK. Email: steve.woolgar@sbs.ox.ac.uk

Keywords: neuromarketing, neuroeconomics, Science and Technology Studies 


\section{Introduction: Neuroscience beyond the lab}

Neuroscientific research studies the brain as a novel means for accessing knowledge about human health, behaviour and social interaction. In recent years a broad range of academic disciplines, professional fields but also artists and lay groups (such as patient groups) have engaged with findings and technologies developed in neuroscience (e.g., Frazzetto and Anker, 2009; Ortega, 2009). In 2012 these developments and its historical antecedents were showcased in a Wellcome Collection ${ }^{1}$ exhibition entitled Brains: the mind as matter. The exhibition sought to “... explore what humans have done to brains in the name of medical intervention, scientific enquiry, cultural meaning and technological change".

This exhibition is a good illustration of how neuroscience has moved beyond the laboratory, a move which has led to what has been described as a 'political economy of brains', that is:

brains are displayed, pictured, scanned, analysed and treated thus transforming them by scientific industry into academic papers, media spectacles of discovery, education and information, healthier citizens, more compliant workers and consumers - all to enhance national prowess, prosperity, security and so on. A multitude of spaces, aesthetic predilections, protocols, technologies and tools supports and enables this range of practices. There is, so to speak, a political economy of brains, by which the brain becomes invested with a level of hope and expectation that has usually exceeded the ability of science to make sense or use of it. (Kwint and Wingate, 2012: 20, our emphasis)

Other examples of neuroscience's move beyond the laboratory abound and include the rapid multiplication of new academic neuro-fields such as neurophilosophy, neurotheology and neurolaw, the proliferation of a wide range of brain 'improvement' products such as pharmaceuticals, brain food, games or books; brain stimulating devices (Brenninkmeijer, 2010); the increasing saturation of media with biological and neurological terminology (Thornton, 2011); and so on. 
So what is it with the brain these days? We editors hosted an international conference with this subtitle in December $2010^{2}$. The aim of the two-day conference was to examine how, why and in what ways the figure of the brain has come to permeate so many different areas of thinking and practice and the likely consequences for academia, business, commerce and policy. In addition to mapping the diffusion of the figure of the brain and exploring its historical specificity, the conference explored how the brain as a trope organises scholarly and commercial thinking in different disciplines and business fields. The conference explored a) the rise and current configuration of the international neuroindustry, b) the economic and social value of the new brain sciences and c) the ethical and social implications of biomarkets and neuromarketing.

This special issue draws on selected conference papers that examine the emergence of two new neuro disciplines, namely neuroeconomics - combining psychology, economics and neuroscience in order to understand the neural impulses behind decision-making - and neuromarketing - the study and management of the brain's response to marketing. Both disciplines promise to advance or even to revolutionise the fields of economics and marketing and with it our current understanding of consumers, citizens, publics and their behaviour. What are the likely consequences? What are the implications for consumer autonomy, the rise and pervasiveness of brand and advertising cultures and the increasing adoption of reductive and/or deterministic models of human behaviour and decision-making? So far sociologists, anthropologists, historians and other social scientists have offered limited scholarly attention to these questions and the neuro-turn in marketing and economics as we 
show in our literature review in the next section. This is particularly noteworthy given the growing attention by social scientists to the neuro-turn in society.

\section{Social studies of neuroscience: a review}

Analogous to the emergence and uptake of neuroscientific knowledge and technologies in a range of academic disciplines and professional fields, we can witness that social scientists have started to direct their attention to studying newly emerging neuroscientific practices and cross-disciplinary engagements over the last decade. These analyses of neuropractices and -disciplines have led to the formation of a new social science sub-discipline frequently described as the "social study of neuroscience' (Choudhury et al, 2009).

Sociological and anthropological contributions to 'social studies of neuroscience' include several edited volumes that offer a good introduction to and focused discussions of what is interchangeably referred to as the "neuroscientific challenge" (Maasen and Sutter, 2007), "neuroculture" (Ortega and Vidal, 2011) or the "neuroscientific-turn" (Littlefield and Johnson, 2012) in the social sciences and humanities. For instance, contributions to Maasen and Sutter's (2007) on the neuroscientific challenge tackle topics such as the discourse on agency in neuroscience and sociology as well as moral evaluations in conceptualizing autonomy. Moreover, Pickersgill and van Keulen (2011) argue for an engagement of social scientists and anthropologists with the 'new brain sciences' in their edited volume that offers Sociological Reflections on the Neurosciences. In their view it has been mostly ethicists who initially turned their attention to the normative and 
epistemological issues neuroscience raises. Their edited volume is an early sociological/anthropological intervention that explores the varied 'social life of the neurosciences' through the eyes of medical anthropologists and sociologists. In the meantime a considerable number of such perspectives has been published in the form of edited volumes (e.g., Ortega and Vidal, 2011; Choudhury and Slaby, 2012), special issues in academic journals (e.g., Vrecko, 2010; Pickersgill et al, 2011), separate journal articles (e.g., Nadesan, 2008; Choudhury et al, 2009; Vidal, 2009; PittsTaylor, 2010; Pickersgill, 2013) and book format (e.g., Thornton, 2011) that discuss and analyse specific neuro-turns in a variety of fields.

A recent addition to the social studies of neuroscience is a book-length discussion that explores key developments that have enabled the neurosciences to gain such prominence (Rose and Abi-Rached, 2013). The book explores the ways neurobiological conceptions of personhood are transforming 'the ways we know ourselves' as human beings and how new concepts of governance are proposed in the light of this new knowledge. Rose and Abi-Rached argue that conceptions of the neuromolecular, plastic, and social brain, could make possible a new and productive engagement between the social and brain sciences.

As Pickersgill (2013) has noted discussions in the social studies of neuroscience literature tend to focus on broad shifts in identity that the meta-narratives of neuroscience seem to have spurred. He points to a risk of overstating transformations in subjectivity that have occurred with and through neuroscience (see also, Pickersgill et al, 2011). This is evident in Choudhury et al.'s (2012) study of British teenager's views of the 'developing teen brain model'. The model developed by cognitive 
scientists based on MRI studies suggests that functions associated with particular brain regions (e.g., cognitive control and social cognition) undergo a period of development in adolescence. These findings form the basis to account for behavioural changes during adolescence. However, Choudhury et al. suggest that based on their research the model seemed to have little impact on teenagers' self-understanding. The teenagers' responses in questionnaires and focus groups tended to be ambivalent or openly resistant toward this model. This example illustrates the importance of conducting empirical research of specific neuro knowledges, technologies and practices in order to understand to what extent, or if at all, transformations in subjectivity occur through neuroscientific research. In addition, such reflexive research permits consideration of possible consequences of reductive and/or deterministic models of human behaviour and the potential effect on human agency.

Our review of the literature on social studies of neuroscience reveals that existing studies focus mainly on the production of knowledge in the laboratory (Cohn, 2004; Joyce, 2008) or analyses of media discourses (Racine et al, 2010; O'Connor et al, 2012). Few publications consider the commercialisation of neuroscientific technologies and knowledges beyond the laboratory and the fields of practice that emerged alongside. Even fewer examine the emergence and development of neuroeconomics and neuromarketing from a social scientists' perspective (but see: Hartmann, 2011; Schüll and Zaloom, 2011; Schneider and Woolgar, 2012). This special issue seeks to fill this gap by offering analyses of the increasing export of neuroscientific knowledge and technologies. How do new products and services travel and with what consequences? How are new neuro markets and industries made? 
This volume meets Choudhury et al.'s (2009) call for a 'critical neuroscience' which brings together an interdisciplinary group of scholars who are engaged in "a reflexive scientific practice that responds to the social, cultural and political challenges posed by the advances in the behavioural and brain sciences" (2009: 61). In particular, the volume offers ethnographic and socio-historical analyses of research fields, professional activities and networks that redefine what is academic and what is commercial research and practice. By focusing on neuromarkets and the commercialisation of neuroscientific knowledges and technologies, this special issue engages reflexively with developments of neuroscience beyond the laboratory. It thereby contributes to developing a more thorough understanding and awareness of the social implications of these practices and their uses.

Finally, this special issue considers the interconnected nature of academic and corporate research (Shapin, 2008) in neuromarketing and neuroeconomics, questions the perceived boundaries between these spheres and seeks to highlight the fluidity (deLaet and Mol, 2000) of these practices. In addition, this special issue considers the relationship between social science analysts and the neuroactors and neuropractices they analyse with a special focus on how sociological/anthropological work coproduces the significance of new disciplinary fields, actors and technologies. By drawing on recent empirical insights into the turn to ontology (Woolgar and Lezaun, 2013; Woolgar and Neyland, 2013; Woolgar and Lezaun, 2015) this special issue highlights how social scientists get entangled with the practices they study and how they assist in enacting new fields and practices. 


\section{Social studies of neuro-markets}

Two contributions to this special issue consider the emergence and development of neuromarketing from different but complementary angles. Whereas Stefan Schwarzkopf (2015) considers neuromarketing and the technologies neuromarketers use from a historical perspective, Schneider and Woolgar's (2015) paper provides an ethnographic account of the development of neuromarketing as a new field of academic and commercial practice. Schwarzkopf introduces us to neuromarketing as a promise. The starting point for his analysis is the promissory power of neuromarketing practices and technologies, the 'marketing of neuromarketing'. In his view the literature on neuromarketing, both critical and celebratory-affirmative versions, submit to this promise in the sense that they consider neuromarketing "as a new development and often as one that brought in a radically new understanding of 'the human' and 'the Self' which underlie the studied brain" (Schwarzkopf, 2015: ? in proof copy).

Schwarzkopf challenges the classification of neuromarketing as a novel market and consumer research practice. He argues that technologies frequently used for neuromarketing purposes, such as functional Magnetic Resonance Imaging (fMRI), electroencephalography (EEG) or eye-tracking can be considered as the latest devices in a series of neurophysiological measurement devices that have been used for consumer research since the 1890s. He shows how devices, such as the tachistoscope, eye cameras, psycho-galvanometers, polygraphs, voltmeters and oscillographs, used for market research purposes since the late $19^{\text {th }}$ century have been re-inscribed as neuro-scientific in the wake of the growing neuromarketing field. Drawing on Deborah Coon's and others' work he situates these neurophysiological measurement 
devices as part of a long tradition in the field of psychology that aims to standardise the subject in industrial modernity (Coon, 1993 and van de Water 1997 as cited in Schwarzkopf, 2015: ? in proof copy).

In addition, Schwarzkopf suggests that neurophysiological research into consumers was underpinned by a posthuman view of the relationship between brain, mind and behaviour from its very beginning in the late $19^{\text {th }}$ century. In other words, consumer researchers employing neurophysiological measurement devices challenged the notion of the consciously deliberating and choosing consumer and suggested that consumer decisions take place at an unconscious level that best could be accessed and captured by machines. However, the views and methods of this particular group of consumer researchers clashed with the views advanced by a more dominant humanist strand of consumer behaviour researchers who emphasised consumers' free will and cognitive abilities when making choices. This humanist group drew on survey questionnaire and focus/discussion groups to allow the researchers verbally to express the reasons for purchasing particular products. Schwarzkopf argues that with the rise of neuromarketing and biometric and neuroscientific technologies the former group and their posthuman view have found a new platform.

Schwarzkopf describes the biopolitical dimension of the entanglement of measurement devices and consumers' bodies/brains as a dispositif. It allows for a new way of seeing consumers and their behavior, and it legitimises neuromarketing practitioners to bypass consumers' verbal accounts and instead focus on physiological reactions. What are the potential implications of this development for consumers? Drawing on Rose (2001), Schwarzkopf suggests that we are faced with "a posthuman 
ethopolitics, that is the view of the body as perfectable prosthesis and the use of neuroscientific research to directly inform social behaviour in a normative sense" (Schwarzkopf, 2015: ? in proof copy). With the help of what Schwarzkopf calls 'neurogovernance devices', such as portable EEG readers that collect measurements of electrical activity of the brain along the scalp (activation levels) and deliver the information to consumers' smartphones, consumers can potentially analyse and adapt their consumption behaviour while shopping. In this scenario, the onus of making 'right' choices rests with consumer-measurement assemblages.

In line with Schwarzkopf's device-centred account of neuromarketing, many articles (both in academic journals and in popular media) define neuromarketing in terms of the technologies it deploys. However, Schneider and Woolgar (2015) problematise this view. In their ethnographic study of neuromarketing as a newly emerging field, they found it difficult to find a "a set of neuromarketers, who would agree on a definition of neuromarketing or who used the same (combination of) technologies, even though they considered themselves to be working 'in the field' of neuromarketing" (2015: page in proof copy ?). Taking the range of interpretations and diverse sets of activities among neuromarketing actors as their starting point, Schneider and Woolgar document the different enactments of neuromarketing in multiple situations and networks. They emphasise how flexible, unstable and moving are the boundaries of neuromarketing that they encountered. They argue that the complex relationship(s) and networks between academic and professional neuromarketers are central for enacting 'legitimate knowledge'. They discuss these issues through a series of ethnographic vignettes in which they describe the different neuromarketings they encountered in their fieldwork. Following an 'ontological 
strategy' (Law and Singleton, 2005) they eschew an analysis of the multiple interpretations of neuromarketing in favour of an analysis of multiple neuromarketings. This enables a detailed description how one or another neuromarketing is enacted into being - including their own enactments, and how neuromarketing performs them. Moreover, the paper discusses the specific challenges their ontological/theoretical commitment raises when facing the issues of collaboration and legitimacy.

Beyond a shared focus on neuromarketing's promissory powers, both Schwarzkopf's, and Schneider and Woolgar's paper highlight the interconnectedness of academic and industrial research in the development of neuromarketing practices and devices and capture aspects of what Shapin (2008) has termed 'new scientific life', i.e., the increasing entrepreneurial attitude guiding university based research with the aim to discover new, patentable technology and/or marketable knowledge that could assist individual researchers in setting up their own company or consultancy. Aspects of this 'new scientific life' are described in both contributions. For instance, Schwarzkopf's offers examples of companies and products that have or are in the process of commercialising portable and wireless EEG scanners that collect real-time data and feed it to consumers' smartphone via a mobile app. Schneider and Woolgar's paper illustrates how it is possible to be perceived as, and invited to be, a strategic neuromarketing research partner based in an academic setting and shows how such interdisciplinary collaborations are actively sought out by practitioners for a variety of reasons - not least to signal academic excellence. 
The entanglement of academic and commercial spheres, as visible in the commercial development of new technologies based on scientific and technical innovation, is further explored in Paul Martin's paper. Martin (2015) examines the creation of a new industrial sector based on the commercial development of neurotechnology in the USA. In particular, he considers the role of expectations and 'promissory organisations' in the making of the neuroindustry. Martin charts the work done by a number of promissory organisations, such as the Neurotechnology Industry Association (NIO, an US-based trade organisation for neurotechnology) and NeuroInsights (a specialist market research, publishing and consultancy firm) showing that trade association and market research firms are central to the definition of the new neuroindustry and the construction of promises around it. In addition, he outlines how the promissory is transformed into the real and how this process is mediated by venture capitalists and market analysts.

Martin's paper addresses an important theme that is prominent in all contributions to this special issue; namely, the promises and expectations that surround the emergence and development of neuromarketing and neuroeconomics. Some papers reflect more, others less, on the enactment of expectations and promises but all acknowledge explicitly or implicitly their centrality for analysing how these new fields and practices are taking shape and how new (economic) values are created. To what extent those reflexively researching these promises and expectations also are implicated in the enactment of neuro fields and practices is discussed, too. For instance, Martin states that in conducting an analysis of two types of promissory organisations, he sought to render different visions of the neuroindustry visible by assembling and reproducing a series of statistics and tables. Similarly Schneider and 
Woolgar emphasise how they as STS researchers are implicated in the ontological work of co-enacting neuromarketing. They discuss how their entanglement with actors and arguments in their ethnographic encounters affects them and how their agency, as STS researchers of neuromarketing practices, is performed in relation to these entanglements. This can be identified as a second theme that is prominent in the papers of this special issue and shifts attention to the manifold entanglements between social science researchers and the neuroactors and -practices they study and beyond that, descriptions of other entanglements such as between (interdisciplinary) collaborations, trade organisations, and research networks.

Isabelle Dussauge (2015) explores yet another aspect of performativity and enactment of values in the bioeconomy or what she describes as the 'emotional economy'. In her analysis of neuroscientific metaphors used in publications of neuroimaging studies of sexuality and of neuroeconomics, she describes the transfers of meaning performed through these metaphors. Dussauge argues that studying what is lost and found in these neurosciences requires us to ask what worlds neuroscientific metaphors are productive of. She notes that "the dynamics of what is invisibilised or generated, backgrounded or foregrounded, lost or found, are the result of socio-cultural work, for instance, of scientists' framing of problems to investigate, and a hierarchization of what they deem worth of scientific inquiry" (2015: page in proof copy ?). Focusing her analysis on notions of reward, she suggests that neuroeconomics and the neuroscience of sex essentialise and economise desire as the driver of our behaviour. In other words, "methaphors re-orient desire, and thereby, the cerebral subject is made a desiring subject, towards certain goals" (2015: page in proof copy ?). Dussauge's description of this as constitutive of an 'emotional economy' echoes Scott Vrecko's 
(2011) description of the 'libidinal economies' which characterise neuroscientific research on addiction.

What can we make of the interdisciplinary engagements or entanglements upon which the papers in this special issue report? What are the implications for social studies of neuromarkets and more broadly for social studies of neuroscience?

\section{Descriptions as interventions in the social studies of neuromarkets and neuroscience}

In their introduction to Critical Neuroscience Choudury and Slaby (2012) argue that it is important for social scientists to find ways to engage with neuroscientists that go beyond mere critique. A similar argument is put forward by Rose and Abi-Rached (see also, Reichertz, 2006):

Rather than fault finding or passing censorious judgement, we are critical here in the sense of "exercising careful judgement or observation; nice, exact, accurate, precise, punctual" [Oxford English Dictionary (OED)]. It is in that critical spirit that we aim to describe the new ways of thinking about the nature of the human brain and its role in human affairs that are taking shape, to consider the problems around which these have formed and the conceptual and technical conditions that have made it possible to think in these ways, $[\ldots] .(2013: 8)$

Rose (2013) also argues that social scientists and scholars in the human sciences need to move beyond commentary and critique and develop a new relation with the life sciences in order to "revitalize themselves for the 21st century" (2013: 3). In sum, Rose and Abi-Rached, and Choudhury and Slaby consider it imperative to find forms of engagement and collaboration with neuroscientists. They envision new types of 
knowledge exchange that take place in inter- or transdisciplinary research projects and networks (see also, Fitzgerald et al, 2014; Fitzgerald and Callard, 2015).

In many ways these modes of knowledge exchange exactly reflect what neuromarketers, neuroeconomists and developers of neuroindustries themselves do. If we agree to view researchers in the disciplines of marketing and economics as social scientists, then their engagement with neuroscience is an inter- or transdisciplinary encounter. What our special issue does, is to offer descriptions of these encounters. These descriptions are provided by another set of social scientists, an historian and sociologists of science and technology, as they observe, reconstruct or analyse the practices or encounters. These descriptions support the idea that researchers in marketing and economics, who reach out, draw on or collaborate with the neurosciences, their knowledge and technologies, are developing a new relationship with the neurosciences and life sciences with the hope to revitalise themselves for the 21 st century. What insights do descriptions of these encounters offer beyond this?

Drawing on recent developments in STS we consider these descriptions as performative in the sense that the objects and actors 'in' the 'field' are enacted in and through these descriptions. Descriptions can thus themselves be understood as interventions (Vikkelsø, 2007; Zuiderent-Jerak and Jensen, 2007; Jensen, 2010). In other words, by studying, engaging with and knowing about the neuro-turn, or other objects or actors, social scientists themselves do/enact the neuro-turn. A corollary of this is that we as social scientists are involved in knowledge production, dissemination and legitimation when we observe and participate in social studies of neuro-collaborations. 
It is perhaps too early to claim that the engagements and explorations articulated in the papers in this special issue constitute a viable alternative to 'critique', not least because of the wholesale vagueness of the latter term. We nonetheless hope that our special issue offers food for thought about a) some of the potential limits of engagement in the form of 'knowledge exchange' between neuro and social scientists and b) examples of reflexive descriptions as interventions into the formation of knowledge in and with the neurosciences. 


\section{References}

Brenninkmeijer, J. (2010) Taking care of one's brain: how manipulating the brain changes people's selves. History of Human Sciences 23(1): 107-126.

Choudhury, S., McKinney, K. A. and Merten, M. (2012) Rebelling against the brain: public engagement with the 'neurological adolescent'. Social Science and Medicine 74(4): 565-573.

Choudhury, S., Nagel, S. K. and Slaby, J. (2009) Critical neuroscience: linking neuroscience and society through critical practice'. BioSocieties 4: 61-77.

Choudhury, S. and Slaby, J. (eds.) (2012) Critical Neuroscience: A Handbook of the Social and Cultural Contexts of Neuroscience. Chichester: Wiley-Blackwell.

Cohn, S. (2004) Increasing resolution, intensifying ambiguity: an ethnographic account of seeing life in brain scans. Economy and society 33(1): 54-76.

deLaet, M. and Mol, A. (2000) The Zimbabwe bush pump: mechanics of a fluid technology. Social Studies of Science 30(2): 225-263.

Dussauge, I. (2015) Sex, Cash and Neuromodels of Desire. BioSocieties 10(4).

Fitzgerald, D. and Callard, F. (2015) Social science and neuroscience beyond interdisciplinarity: experimental entanglements. Theory, Culture \& Society 32(1): 3-32.

Fitzgerald, D., Littlefield, M. M., Knudsen, K. J., Tonks, J. and Dietz, M. J. (2014) Ambivalence, equivocation and the politics of experimental knowledge: A transdisciplinary neuroscience encounter. Social Studies of Science 44(5): 701-721.

Frazzetto, G. and Anker, S. (2009) Neuroculture. Nature Reviews Neuroscience 10: 815-821.

Hartmann, M. (2011) Neuroökonomie und Neurokapitalismus. Am Beispiel des Vertrauens. Deutsche Zeitschrift für Philosophie 59(3): 391-402.

Jensen, C. B. (2010) Ontologies for Developing Things: Making Health Care Futures Through Technology. Rotterdam: Sense Publishers.

Joyce, K. A. (2008) Magnetic Appeal: MRI and the Myth of Transparency. Ithaca: Cornell University Press. 
Kwint, M. and Wingate, R. (2012) Brains: Mind as Matter. London: Wellcome Collection.

Law, J. and Singleton, V. (2005) Object lessons. Organization 12(3): 331-355.

Littlefield, M. M. and Johnson, J. M. (2012) The Neuroscientific Turn: Transdisciplinarity in the Age of the Brain. Ann Arbor, MI: University of Michigan Press.

Maasen, S. and Sutter, B. (eds.) (2007) On Willing Selves. Neoliberal Politics vis-àvis the Neuroscientific Challenge. Basingstoke: Palgrave Macmillan.

Martin, P. (2015) Commercialising neurofutures: promissory economies, value creation and the making of a new industry. BioSocieties 10(4): tbc.

Nadesan, M. H. (2008) Governmentality, biopower, and everyday life. New York: Routledge.

O'Connor, C., Rees, G. and Joffe, H. (2012) Neuroscience in the public sphere. Neuron 74: 220-226.

Ortega, F. (2009) The cerebral subject and the challenge of neurodiversity. BioSocieties 4: 425-445.

Ortega, F. and Vidal, F. (eds.) (2011) Neurocultures: Glimpses into an Expanding Universe. Frankfurt am Main: Peter Lang.

Pickersgill, M. (2013) The social life of the brain: neuroscience in society. Current Sociology 61(3): 322-340.

Pickersgill, M., Cunningham-Burley, S. and Martin, P. (2011) Constituting neurologic subjects: neuroscience, subjectivity and the mundane significance of the brain. Subjectivity 4(3): 346-365.

Pickersgill, M. and van Keulen, I. (eds.) (2011) Sociological Reflections on the Neuroscience. Bingley, UK: Emerald Group Publishing.

Pitts-Taylor, V. (2010) The plastic brain: neoliberalism and the neuronal self. Health 14(6): 635-652.

Racine, E., Waldman, S., Rosenberg, J. and Illes, J. (2010) Contemporary neuroscience in the media. Social Science and Medicine 71: 725-733.

Reichertz, J. (2006) Akteur Gehirn - oder das vermeintliche Ende des sinnhaft handelnden und kommunizierenden Subjekts. In: REICHERTZ, J. \& 
ZABOURA, N. (eds.) Akteur Gehirn - oder das vermeintliche Ende des handlenden Subjekts. Wiesbaden: VS Verlag für Sozialswissenschaften.

Rose, N. (2001) The politics of life itself. Theory, Culture \& Society 18(6): 1-30.

Rose, N. (2013) The human sciences in a biological age. Theory, Culture \& Society 30(1): 3-34.

Rose, N. and Abi-Rached, J. (2013) Neuro: the new brain sciences and the management of the mind. Princeton, New Jersey: Princeton University Press.

Schneider, T. and Woolgar, S. (2012) Technologies of ironic revelation: enacting consumers in neuromarkets. Consumption Markets \& Culture 15(2): 169189.

Schneider, T. and Woolgar, S. (2015) Neuromarketing in the making: enactment and reflexive entanglement in an emerging field. BioSocieties 10(4): tbc.

Schüll, N. D. and Zaloom, C. (2011) The shortsighted brain: neuroeconomics and the governance of choice in time. Social Studies of Science 41(4): 515-538.

Schwarzkopf, S. (2015) Measurement devices and the psychophysiology of consumer behaviour: a posthuman genealogy of neuromarketing. BioSocieties 10(4): tbc.

Shapin, S. (2008) The Scientific Life. A Moral History of a Late Modern Vocation. Chicago: Chicago University Press.

Thornton, D. J. (2011) Brain Culture: Neuroscience and Popular Media. New Brunswick, NJ: Rutgers University Press.

Vidal, F. (2009) Brainhood, anthropological figure of modernity. History of Human Sciences 22: 5-36.

Vikkels $\varnothing$, S. (2007) Description as intervention: engagement and resistance in actor-network analyses. Science as Culture 16(3): 297-3-9.

Vrecko, S. (2010) Neuroscience, power and culture: an introduction. History of the Human Sciences 23: 1-10.

Vrecko, S. (2011). Addiction, science and libidinal economies: towards a decentering of the reward system? International Seminar: Addicts as Biocitizens? Neurobiology, Addiction and Society. The Sahlgrenska Academy, Goeteborg. 
Woolgar, S. and Lezaun, J. (2013) The wrong bin bag: a turn to ontology in science and technology studies? Social Studies of Science 43(3): 321-340.

Woolgar, S. and Lezaun, J. (2015) Missing the (question) mark: what is the turn to ontology? Social Studies of Science 45(3): 462-467.

Woolgar, S. and Neyland, D. (2013) Mundane Governance: Ontology and Accountability. Oxford: Oxford University Press.

Zuiderent-Jerak, T. and Jensen, C. B. (2007) Editorial introduction: Unpacking 'intervention' in science and technology studies. Science as Culture 16(3): 227-235. 


\section{Bios:}

Steve Woolgar is Professor of Science and Technology Studies at Tema $\mathrm{T}$ (Technology and Social Change), Linköping University, and Chair of Marketing at

Saïd Business School, University of Oxford. His recent publications include: Mundane Governance: ontology and accountability (with Daniel Neyland, OUP 2013); Representation in Scientific Practice Revisited (with Mike Lynch, Catelijne Coopmans and Janet Vertesi, MIT 2014); Globalization in Practice (with Nigel Thrift and Adam Tickell, OUP, 2014); and Visualisation in the Age of Computerisation (with Annamaria Carusi, Aud Hoel and Tim Webmoor, Routledge, 2015). In addition to working on the impact of the neurosciences on social sciences and the humanities, he is preparing a book length exploration of the nature and limits of provocation.

Tanja Schneider is a senior lecturer in Sociology at the Institute of Sociology, University of St. Gallen, and an associate fellow at the Institute for Science, Innovation and Society (InSIS), University of Oxford. She studies the emergence, development and social implications of neuromarketing from a Science and Technology Studies perspective funded through an ESRC Open Research Area (ORA) project. Tanja is also a James Martin Fellow in the Oxford Martin Programme on the Future of Food at the University of Oxford. She examines the ways in which new media shape consumer activism and food governance in Europe with members of the Oxford Food Governance Group. 


\section{Acknowledgements:}

We would like to thank the European Neuroscience and Society Network (ENSN), London School of Economics and Political Sciences/King's College London, and the Institute for Science, Innovation and Society (InSIS), University of Oxford, for generously sponsoring a two-day international conference entitled 'Neurosociety... what is it with the brain these days' that we organised at the Saïd Business School in December 2010. Thank you to all members of ENSN and InSIS, and conference participants for their contributions and for making the conference such a stimulating and successful event. Finally, we would like to thank the editors of BioSocieties for their support and constructive feedback. 


\section{Notes}

${ }^{1}$ The Wellcome collection is a museum in London, United Kingdom, that is funded by the Wellcome Trust, which is the world's largest independent charitable foundation funding research into human and animal health. The exhibition ran from end of March to mid June 2012. More information is available online: http://www.wellcomecollection.org/whatson/exhibitions/brains.aspx [accessed 6 May 2013].

${ }^{2}$ The conference was co-organised by the European Neuroscience and Society Network (ENSN) and the Institute for Science Innovation and Society (InSIS) and hosted at the Said Business School, University of Oxford, on December $7^{\text {th }}$ and $8^{\text {th }}, 2010$. For more information see: http://www.sbs.ox.ac.uk/school/events-0/neurosociety-conference-what-itbrain-these-days [accessed 10 August 2015]. 